\title{
Updating the geographical distribution and frequency of Aedes albopictus in Brazil with remarks regarding its range in the Americas
}

\author{
Roberta Gomes Carvalho ${ }^{1 /+}$, Ricardo Lourenço-de-Oliveira ${ }^{2}$, Ima Aparecida Braga ${ }^{1}$ \\ ${ }^{1}$ Secretaria de Vigilância em Saúde, Ministério da Saúde, Brasília, DF, Brasil \\ ${ }^{2}$ Laboratório de Transmissores de Hematozoários, Instituto Oswaldo Cruz-Fiocruz, Rio de Janeiro, RJ, Brasil
}

\begin{abstract}
The geographical distribution of Aedes albopictus in Brazil was updated according to the data recorded across the country over the last eight years. Countrywide house indexes (HI) for Ae. albopictus in urban and suburban areas were described for the first time using a sample of Brazilian municipalities. This mosquito is currently present in at least 59\% of the Brazilian municipalities and in 24 of the 27 federal units (i.e., 26 states and the Federal District). In 34 Brazilian municipalities, the HI values for Ae. albopictus were higher than those recorded for Ae. aegypti, reaching figures as high as HI $=7.72$ in the Southeast Region. Remarks regarding the current range of this mosquito species in the Americas are also presented. Nineteen American countries are currently infested and few mainland American countries have not confirmed the occurrence of Ae. albopictus. The large distribution and high frequency of Ae. albopictus in the Americas may become a critical factor in the spread of arboviruses like chikungunya in the new world.
\end{abstract}

Key words: Aedes albopictus - distribution - house index - infestation - surveillance

Aedes albopictus (Skuse), also known as the Asian tiger mosquito, was first described 120 years ago based on specimens collected in Calcutta, India (Zeller 1998). Its original distribution included Southeast Asia, the islands of the Pacific and Indian Oceans, northern China, Japan and Madagascar. It has since spread from this original range to dozens of countries across all continents (Lounibos 2002). Thus, Ae. albopictus is considered one of the most important invasive species worldwide (Benedict et al. 2007, Medlock et al. 2012). It is likely that the intense trading of used tires containing eggs has favoured the wide dispersion of this species over recent decades, particularly beginning in the 1980s; the intercontinental traffic of other goods and varied routes have also been suggested as passive dispersal mechanisms (Reiter 1998, Lounibos 2002, Benedict et al. 2007, Paupy et al. 2009). Its colonisation of temperate regions such as North America and Europe as well as tropical and subtropical regions such as South America and Africa was facilitated by the species' strong biological and behavioural plasticity, including its use of a substantial variety of larval habitats (e.g., artificial and natural containers), highly competitive ability during the larval stage, relative resistance to low temperatures, and other unfavourable environmental conditions during both immature and adults stages, and ability to colonise both humanmade and natural environments (e.g., near human dwell-

doi: 10.1590/0074-0276140304

+ Corresponding author: roberta.carvalho@saude.gov.br

Received 20 August 2014

Accepted 26 August 2014 ings, non-residential areas and forest fringes) (Reiter \& Sprenger 1987, Hawley 1988, Estrada-Franco \& Craig Jr 1995, Lounibos et al. 2003, Lourenço-de-Oliveira et al. 2003, Juliano \& Lounibos 2005, Paupy et al. 2009, Fernández et al. 2012, Lima-Camara et al. 2013). Immature forms of Ae. albopictus are found in natural deposits such as bromeliads, tree holes and bamboo and its larvae can also co-occur and compete with those of Aedes aegypti in human-made containers (Consoli \& Lourençode-Oliveira 1994, Natal et al. 1997, Forattini 2002).

The first report of Ae. albopictus colonisation in the Americas was made in August 1985 in Houston, Texas, United States of America (USA) (Sprenger \& Wuithiranyagool 1986). Ae. albopictus was detected for the first time in Brazil in 1986 in the states of Rio de Janeiro (RJ) and Minas Gerais (MG), located in the Southeast Region of the country (Consoli \& Lourenço-de-Oliveira 1994). Actually, in May 1986, one of us (RLO) received a batch of mosquitoes bred from larvae collected in a container in the urban area of Viçosa, MG, by Prof Paulo Fiuza Ferreira. He reared the mosquitoes to know if they were Ae. aegypti, which was responsible for a severe dengue outbreak in Rio de Janeiro, about $300 \mathrm{Km}$ from his city. Although the specimens were poorly preserved, it was perceived that they did not belong to any known Neotropical species of Aedes. Almost one month later, a student of Federal Rural University of Rio de Janeiro collected mosquito larvae in an abandoned tire in the university campus, at Seropédica, RJ, taking them to his teacher, Prof Eugênio Izelkson. They reared the larvae supposing they were Ae. aegypti, but when the first adults emerged, they were seen not to belong to this species. On 22 June, Prof Izelkson was watching a TV program on the invasion of Ae. albopictus in the USA, when a close-up of this mosquito was shown; he immediately assumed that his mosquitoes probably belonged to that species. On 
the following day, he advised the health authorities, the Brazilian Superintendence of Public Health Campaigns (SUCAM), and sent some specimens to be identified by one of us (RLO) and the late Prof Leonidas M Deane. On 24 and 25 June, after examining females, males, male genitalia and larvae from Seropédica, and comparing them with the specimens caught in Viçosa, we (RLO and LMD) identified all specimens as Ae. albopictus, a diagnosis subsequently confirmed by Prof Oswaldo P Forattini, who also made the same diagnosis using specimens from the same batch. The surveys conducted by SUCAM in the Southeast Region detected this species in the states of São Paulo (SP) that same year and in Espírito Santo (ES) the following year.

The first invasion in Brazil was hypothesised to have occurred through the ports located in ES and the species most likely gained access to other states via the railway network. It is likely that more than one invasion and colonisation event has occurred at different sites and times since the 1980s by Ae. albopictus founder populations with distinct origins (Consoli \& Lourençode-Oliveira 1994, Lounibos 2002, Lounibos et al. 2003, Lourenço-de-Oliveira et al. 2003, Usmani-Brown et al. 2009, Vidal et al. 2012).

In Brazil, the population density of Ae. aegypti is periodically accessed to direct and evaluate control measures (MS 2009, Coelho 2012). The surveillance of Ae. aegypti infestation levels in Brazil has been performed in each state and data have regularly been stored since 1997, when the National Health Foundation created a database for entomological data called the Yellow Fever and Dengue Information System (SISFAD) (dos Santos 2003). Therefore, the geographic distribution and house index (HI) of Ae. aegypti in Brazil is frequently updated (Coelho 2012). However, this information is fragmented, out-dated or even absent for Ae. albopictus (dos Santos 2003). In fact, Ae. albopictus has never been considered natural vector of arboviruses in Brazil or in any other American country. Thus, its surveillance has not been prioritised. Despite not being the target species of the DENV control program, immature stages of Ae. albopictus have been detected and recorded during routine entomological surveys of $A e$. aegypti in Brazil. However, these records have not been analysed or made available for over 10 years (dos Santos 2003). Nevertheless, experiments have demonstrated that Ae. albopictus populations from Brazil and other American countries are highly competent at transmitting dengue (DENV), Yellow fever (YFV) and Chikungunya (CHIKV) (Mitchell et al. 1987, Miller et al. 1989, Lourenço-deOliveira et al. 2003, Vega-Rua et al. 2014). The recent circulation of CHIKV in the Caribbean (Nasci 2014) and the high vector competence of Ae. albopictus populations from Brazil and nine other American countries to transmit two CHIKV genotypes (Vega-Rua et al. 2014) underscores the need for updating the knowledge of this mosquito species' distribution and frequency to better target timely preventive and control measures.

Therefore, the current paper updates the information on the geographic distribution of Ae. albopictus in Brazil according to the data recorded across the country over the last eight years. Furthermore, this study is the first to describe the countrywide HI of this mosquito in urban and suburban areas using a sample of Brazilian municipalities chosen by the National Program for Dengue Control (PNCD).

\section{MATERIALS AND METHODS}

The current analysis was based on the data recorded by each Brazilian municipality according to annual larval surveys conducted from 2007-2014. The primary data were collected using two methodologies applied for the entomological surveillance of the PNCD: (i) the houseto-house larval survey (LI), which determines the most traditional Stegomyia index (i.e., the HI, whose data are routinely stored in the SISFAD), and (ii) the Rapid Assessment of Infestation by Aedes aegypti (LIRAa) (Pilger et al. 2011, Coelho 2012).

In the LI procedure, health agents search larval habitats over two consecutive months in $100 \%, 33 \%, 20 \%$ or $10 \%$ of municipal premises (depending on the number of buildings in the municipality) as recommended by the WHO (2009) and MS $(2005,2009)$. The LI was done in of 5,562 municipalities. The HI corresponds to the percentage of houses with at least one positive larval habitat.

The methodology used for the LIRAa was also based on the detection of immature mosquito forms. However, the LIRAa consists of dividing municipalities into strata of 8,100-12,000 premises (residential or commercial buildings), depending on the municipality's population density (MS 2005). The sampling is performed using premise clusters containing two sampling units: block and premise. The initial sample size is calculated based on the stratum size, with a maximum sample size of 450 houses. The number of randomly sorted blocks to be surveyed was calculated based on the mean block size, as described by Pilger et al. (2011). Using this methodology, around $5 \%$ of the total premises were inspected in one week visited in each municipality (MS 2005).

Since 2003, the PNCD has defined certain municipalities as a priority for performing a nationwide LIRAa (MS 2006). The nationwide LIRAa has conducted on a bimonthly basis each year in October or November, which is at the beginning of the rainy and DENV transmission seasons in most Brazilian territories. The municipalities were classified as infested when the occurrence of Ae. albopictus was confirmed via either LI or LIRAa inspection during at least one of the annual surveys conducted between 2007-2014 (MS 2009).

The historical analysis of the HI values was based on the nationwide LIRAa data collected from 2007-2011 because the primary data gathered from 2012-2014 had not yet been fully verified or recorded for all Brazilian municipalities. The number municipalities prioritised for the nationwide LIRAa has increased annually according to the criteria established by the CG-PNCD. From 20072009, 169 municipalities were annually surveyed $(3 \%$ of Brazilian municipalities); in 2010 and 2011, 427 (7.5\%) and $665(12 \%)$ municipalities were included, respectively (MS 2006). The ratios between the HI values found for Ae. aegypti and Ae. albopictus were calculated and the municipalities where the HI values for Ae. albopictus were greater than those for Ae. aegypti were identified. 


\section{RESULTS}

The geographical distribution of Ae. albopictus in Brazil - In 2014, Ae. albopictus was detected in 59\% of the 5,565 surveyed Brazilian municipalities $(n=3,285)$. A $51.6 \%$ increase in the number of infested municipalities was observed compared to 2011 (Fig. 1). The LI and LIRAa, performed from 2007-2012, recorded the occurrence of Ae. albopictus in 23 of the 27 Brazilian federal units (i.e., 26 states and the Federal District). Ae. albopictus showed a wider geographical distribution in the Southeast, South and Central-West, where 1,489 (89.3\%), $748(63 \%)$ and 245 (52.6\%) municipalities were infested, respectively. The percentages of infested municipalities were much lower in the North (139 municipalities, 31\%) and Northeast (663; 37\%) (Fig. 1).

The historical evolution of the HI by Ae. albopictus across Brazilian municipalities from 2007-2011 - Fig. 2 shows the HI values in the Brazilian municipalities surveyed by the nationwide LIRAa between 2007-2011. Twenty-one municipalities in the North, Northeast, South and Southeast exhibited HI values $\geq 0.9$ for Ae. albopictus in at least one of annual surveys. The highest HI values for Ae. albopictus were recorded in the municipalities of Teresópolis (RJ) in the Southeast in 2008, Florianópolis, Santa Catarina (SC) in the South in 2009, Mario Campos (MG) in the Southeast in 2010 and 2011, Muriaé (MG) and Cariacica (ES) in the Southeast in 2011. Remarkably, the great majority of municipalities recording the highest annual HI values for Ae. albopictus in Brazil were in the Southeast (Table I). HI reached values as high as 7.72 in the Southeast, as in Mario Campos (MG) (Table I). In the Southeast Region, some municipalities reported HI values for Ae. albopictus several fold higher that those detected for Ae. aegypti (Table II), such as in Teresópolis and Mario Campos (ratios $=5.28$ and 16.83, respectively).

The HI values for Ae. albopictus were higher than those reported for Ae. aegypti in 34 Brazilian municipalities. These areas included (i) the South Region [Porto Alegre, Rio Grande do Sul in 2008, Florianópolis (SC) in 2008, 2009 and 2010, Apucarana and Cambé, Paraná (PR) in 2011], (ii) the North Region [Presidente Figueiredo, Iranduba, Novo Airão, Rio Preto da Eva and Tabatinga (Amazonas), in 2011], (iii) the Northeast Region [Moreno, Pernambuco in 2010, Parnamirim, Rio Grande do Norte in 2011] and (iv) the Southeast Region [Santa Luzia (MG) in 2007 and 2010, Ibirité and Sabará (MG), Angra dos Reis, Rezende and Teresópolis (RJ) in 2008, Guapimirim and Itatiaia (RJ), Mário Campos (MG) in 2010 and 2011, Piraí and Porciúncula (RJ), Além Paraíba and Confins (MG) in 2010, Marataízes and Cariacica (ES), Itanhaém and Peruíbe (SP), Aperibé, Engenheiro Paulo de Frontin, São Francisco de Itabapoana (RJ), Caratinga, Manhuaçu and Muriaé (MG) in 2011]. The HI values for Ae. albopictus were lower than those recorded for Ae. aegypti for all municipalities from the CentralWest, regardless of year.

\section{DISCUSSION}

This paper provides the first description of the geographic distribution of Ae. albopictus in Brazil at the municipal level and assesses the HI values recorded for this species vs. those reported for Ae. aegypti in municipalities sampled across the country.

A noticeable and increased spread of Ae. albopictus was detected in Brazil since the last evaluation (dos San-

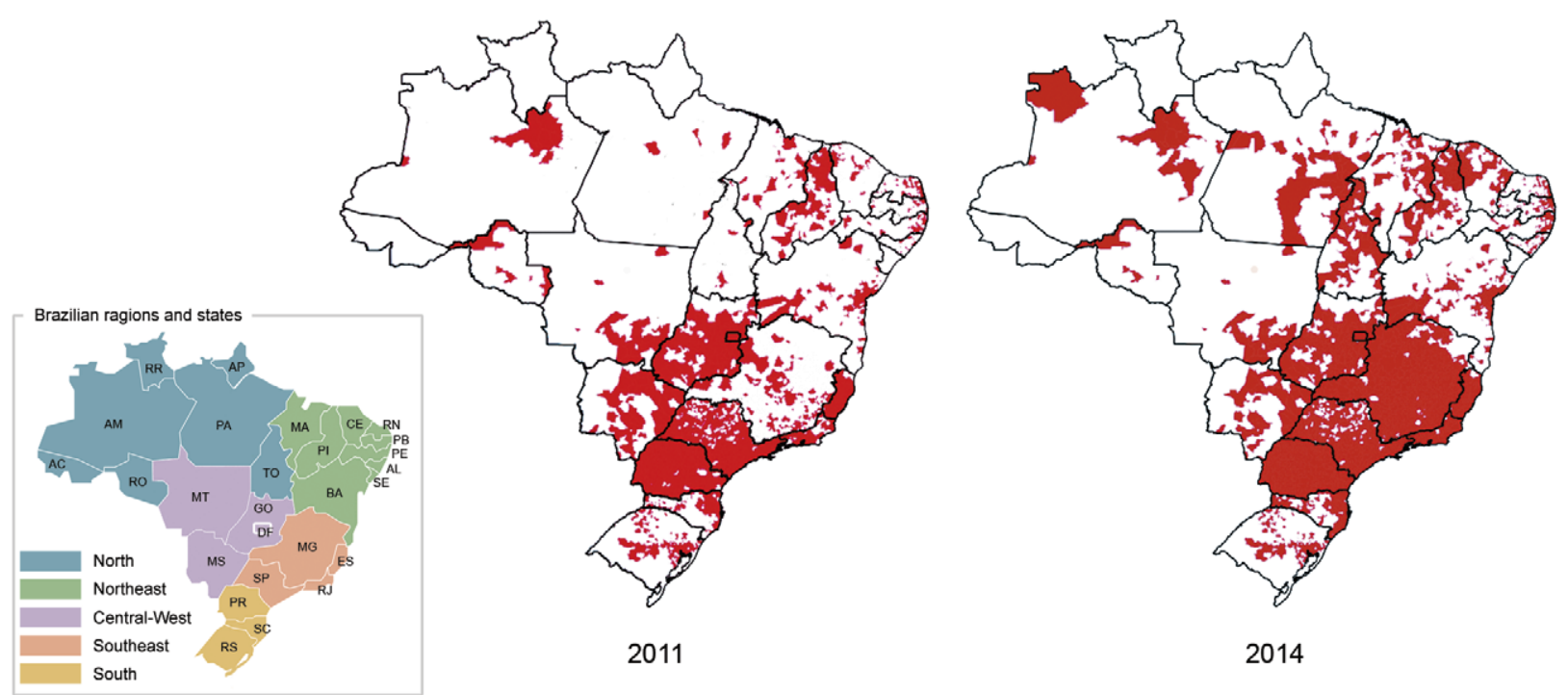

Fig. 1: Brazilian municipalities were Aedes albopictus was detected in 2011 and 2014. AC: Acre; AL: Alagoas; AM: Amazonas; AP: Amapá; BA: Bahia; CE: Ceará; DF: Federal District; ES: Espírito Santo; GO: Goiás; MA: Maranhão; MG: Minas Gerais; MS: Mato Grosso do Sul; MT: Mato Grosso; PA: Pará; PB: Paraíba; PE: Pernambuco; PI: Piauí; PR: Paraná; RJ: Rio de Janeiro; RN: Rio Grande do Norte; RO: Rondônia; RR: Roraima; RS: Rio Grande do Sul; SC: Santa Catarina; SE: Sergipe; SP: São Paulo; TO: Tocantins. 


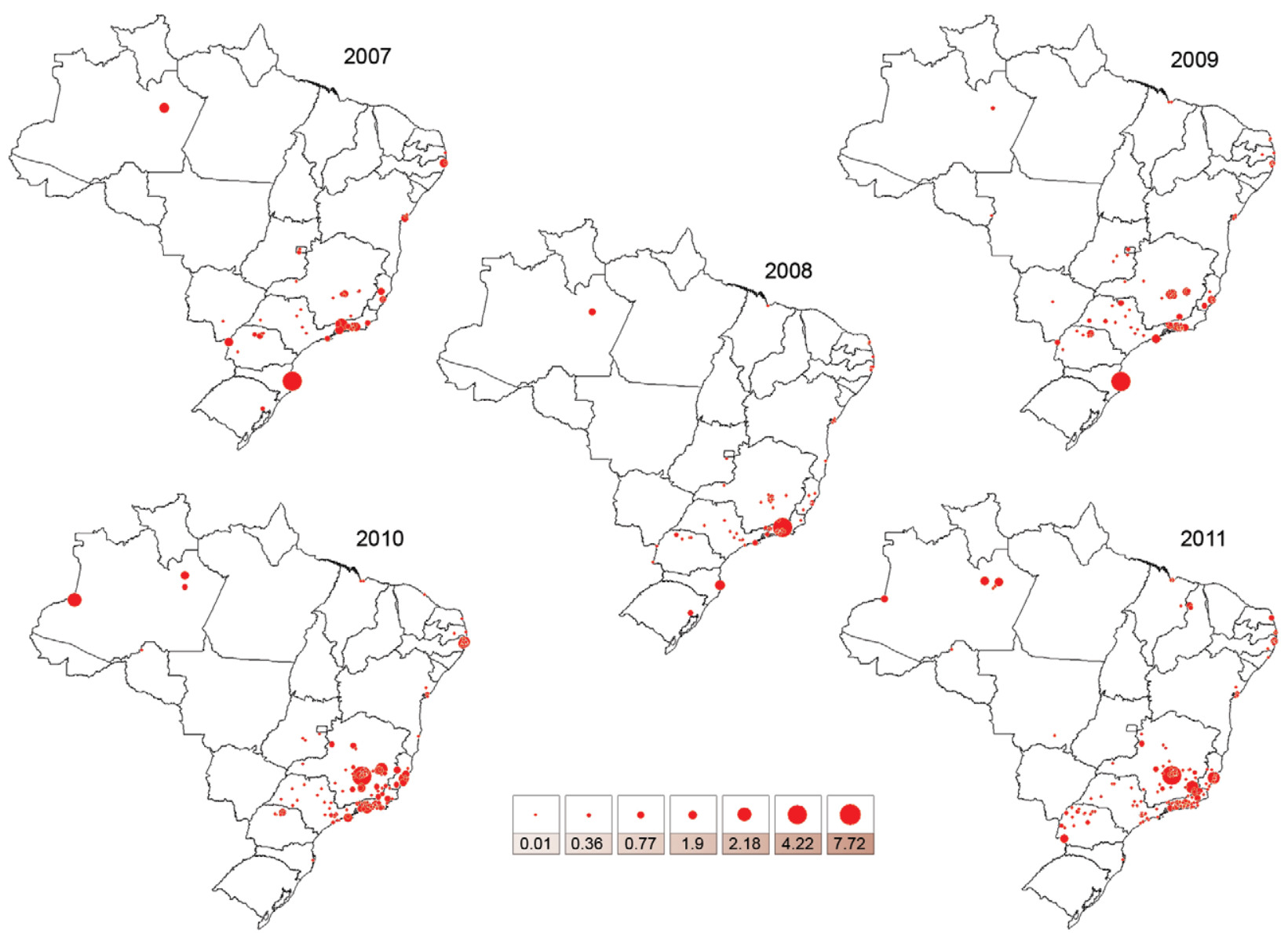

Fig. 2: variation of house index for Aedes albopictus in Brazilian surveyed municipalities from $2007-2011$.

tos 2003). According to dos Santos (2003), seven Brazilian states did not report the presence of this mosquito species until 2002: Acre (AC), Amapá (AP), Roraima (RR), Tocantins, Piauí, Ceará and Sergipe (SE). However, according to the data gathered in the SISFAD and LIRAa assessments from 2007-2014, this mosquito species was detected in all but the following four states: AC, AP, RR and SE. Although not detected by the LI and LIRAa surveys performed in RR between 2007-2014, Aguiar et al. (2008) found immature forms of Ae. albopictus in this state in 2006 and 2007. In conclusion, only three of the 27 Brazilian federal units did not report the presence of this mosquito species.

Unfortunately, neither the HI values for this species nor previous detailed data (dos Santos 2003) regarding the number of municipalities infested by Ae. albopictus exist in Brazil at the national level. Therefore, we cannot assess whether these indicators have recently increased. Importantly, Ae. albopictus is present in more than half of all Brazilian municipalities (59\%) and it has the largest geographic distribution and the highest reported HI values in municipalities and states located in the Southeast. Likewise, Ae. albopictus was first found in Brazil in the Southeast (Consoli \& Lourenço-de-Oliveira 1994).

It is likely that the geographical distribution of $A e$. albopictus remains underestimated in Brazil. It is pos- sible that this mosquito species might be present in certain municipalities classified herein as negative. Three major methodological issues and limitations in LI and LIRAa may reduce the detection rate for this mosquito. The first limitation is the low sample size of the LI and LIRAa surveys ( $\mathrm{n} \leq 10$ larvae/positive larval habitat). As a result, in larval sites where Ae. albopictus is much less frequent than Ae. aegypti, the probability of detecting the former species becomes very low. The second is related to the sample site locations targeted by LI and LIRAa, which only focus on the target species, $A e$. aegypti, and do not consider the essentially extradomiciliary behaviours of Ae. albopictus that might include the colonisation of Brazilian forest fringes (Albuquerque et al. 2000, Lourenço-de-Oliveira et al. 2004). In fact, the data analysed herein correspond to the records of larval collections made in urban areas, mostly in containers located inside or within the close vicinity of houses. However, Ae. albopictus is usually uncommon in these environments in Brazil, which strongly reduces the chance of finding its larvae during the LI and LIRAa surveys. Braks et al. (2003) demonstrated that the frequency of Ae. albopictus in Southeast of Brazil is directly and positively correlated with vegetation coverage and shows a negative relationship with increasing urbanisation. Finally, the third metrological issue is 
TABLE I

Brazilian municipalities where the house index values were higher than 0.9 from 2007-2011, according to the nationwide Rapid Assessment of Infestation by Aedes aegypti

\begin{tabular}{|c|c|c|c|c|c|c|c|}
\hline Region & State & Municipality & 2007 & 2008 & 2009 & 2010 & 2011 \\
\hline $\mathrm{N}$ & $\mathrm{AM}$ & Novo Airão & NR & NR & NR & NR & 1.9 \\
\hline $\mathrm{N}$ & AM & Rio Preto do Eva & NR & NR & NR & NR & 1.71 \\
\hline $\mathrm{N}$ & $\mathrm{AM}$ & Tabatinga & NR & NR & NR & 2.18 & 1.38 \\
\hline $\mathrm{NE}$ & PE & Camaragibe & 0.4 & 0.23 & 0.5 & 1.68 & 1.4 \\
\hline $\mathrm{NE}$ & $\mathrm{PE}$ & Moreno & NR & NR & NR & 1.25 & 0.2 \\
\hline $\mathrm{SE}$ & $\mathrm{RJ}$ & Aperibé & NR & NR & NR & 0 & 1.15 \\
\hline $\mathrm{SE}$ & $\mathrm{RJ}$ & Conceição de Macabu & NR & NR & NR & 0.53 & 1.02 \\
\hline SE & $\mathrm{RJ}$ & Guarapimirim & NR & NR & NR & 0.7 & 1.88 \\
\hline SE & RJ & Itaguaí & NR & NR & NR & 1.38 & 0.82 \\
\hline SE & RJ & Teresópolis & NR & 5.05 & NR & NR & NR \\
\hline SE & MG & Dores do Indaiá & NR & NR & NR & 0.22 & 1.03 \\
\hline $\mathrm{SE}$ & MG & Ipaba & NR & NR & NR & 1.77 & NR \\
\hline SE & MG & Mario Campos & NR & NR & NR & 4.22 & 7.72 \\
\hline SE & MG & Muriaé & NR & NR & NR & 0.18 & 3.25 \\
\hline SE & MG & Ribeirão da Neves & 0.13 & 0.38 & 1.06 & 0.22 & 0.40 \\
\hline $\mathrm{SE}$ & MG & Santa Cruz das Minas & NR & NR & NR & 0.91 & NR \\
\hline SE & MG & Timóteo & 0.08 & 0.08 & 0.94 & 0.95 & 0.32 \\
\hline SE & ES & Cariacica & 0.28 & 0.24 & 0.80 & 1.21 & 3.45 \\
\hline SE & SP & São Sebastião & 0.23 & 0.50 & 1.00 & 0.95 & 0.05 \\
\hline $\mathrm{S}$ & $\mathrm{SC}$ & Florianopolis & 2.04 & 1.45 & 4.16 & 0.19 & 0.02 \\
\hline $\mathrm{S}$ & PR & Capanama & NR & NR & NR & NR & 1.78 \\
\hline
\end{tabular}

the number of municipalities annually surveyed were 169 in 2007-2009, 427 in 2010 and 665 in 2011. NR: not realised; Brazilian Regions: North (N), Northwest (NE), South (S), Southeast (SE); states: Amazonas (AM), Espírito Santo (ES), Minas Gerais (MG), Paraná (PR), Pernambuco (PE), Rio de Janeiro (RJ), Santa Catarina (SC), São Paulo (SP).

related to potential larval misidentification, especially in states or counties where Ae. albopictus does not traditionally or frequently occur. In addition, the entomological surveillance seeking to control DENV in Brazil (i.e., LI and LIRAa) is limited to municipal urban and suburban areas; no data exist for rural areas. Thus, it is likely that Ae. albopictus is present in more than 59\% of all Brazilian municipalities and the lack of Ae. albopictus records in certain counties is simply because this species is not yet a priority target species.

Because its extradomiciliary behaviour, detecting immature forms of Ae. albopictus using the current LI and LIRAa methodologies is much less likely compared to Ae. aegypti (Consoli \& Lourenço-de-Oliveira 1994, Forattini 2002, Honório et al. 2009). Consequently, as might be expected, the HI values for Ae. aegypti are traditionally higher than those detected for Ae. albopictus across Brazil. Nonetheless, the HI values for $A e$. albopictus were higher than those reported for Ae. aegypti in at least 34 Brazilian municipalities, $67.7 \%$ of which are located in the Southeast.

Ae. albopictus has been present in urban and suburban areas of all Brazilian regions for decades and its territory overlaps that of Ae. aegypti. Furthermore, LI and LIRAa often found immature forms of Ae. albopictus in association with those of Ae. aegypti. In fact, Ae. albopictus might be abundant in urban and suburban areas where artificial containers are commonly accumulated at open fields in the backyards, as described in Nova Iguaçu (RJ) in the Southeast (Braks et al. 2003). The population density of Ae. albopictus at Ubiratã (PR) in the South was higher than that of Ae. aegypti, even in urban centres (Prophiro et al. 2011). Therefore, although Ae. albopictus is not common inside human dwellings in Brazil, its density can be high in backyards and in the transition zone between human-made and natural environments (Lourenço-deOliveira et al. 2004, Honório et al. 2009). These behaviours and distributions increase the chances of human infection due to the arboviruses (e.g., YFV, DENV and CHIKV) that the Brazilian Ae. albopictus populations have been shown to be competent to transmit (Lourenço-de-Oliveira et al. 2003, Vega-Rua et al. 2014). Furthermore, the ability of Ae. albopictus females to move between the forest and human-made environments (Lourenço-de-Oliveira et al. 2004, Maciel-de-Freitas et al. 2006) might favour the dissemination of forest-restricted arboviruses such as YFV (Lourenço-de-Oliveira et al. 2003).

The range of Ae. albopictus in the Americas has significantly increased since its first detection early in the 1980's (Benedict et al. 2007). Currently, the colonisation of Ae. albopictus has been confirmed in 19 countries (Fig. 3): Brazil, Paraguay, Colombia, Venezuela, Trini- 


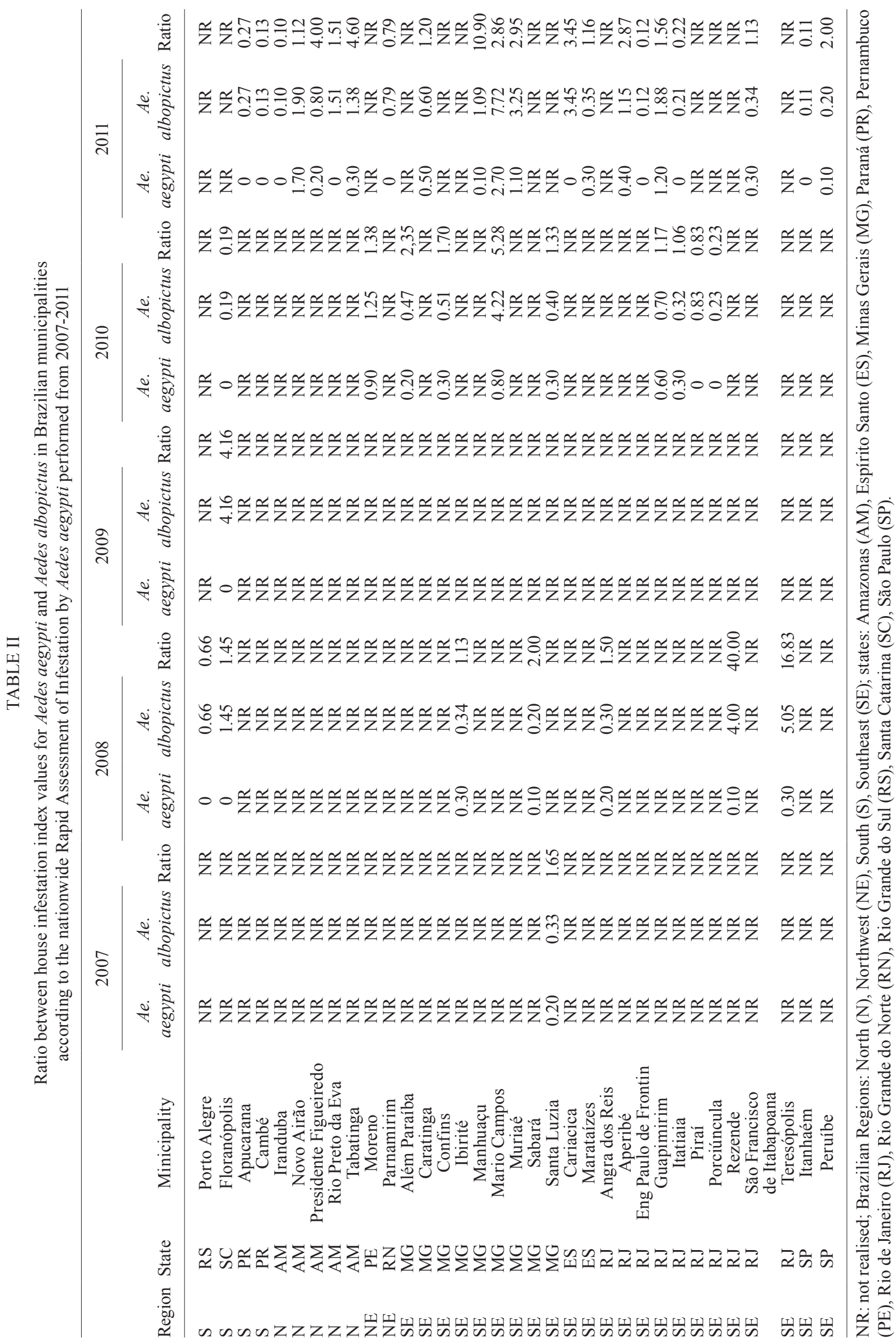




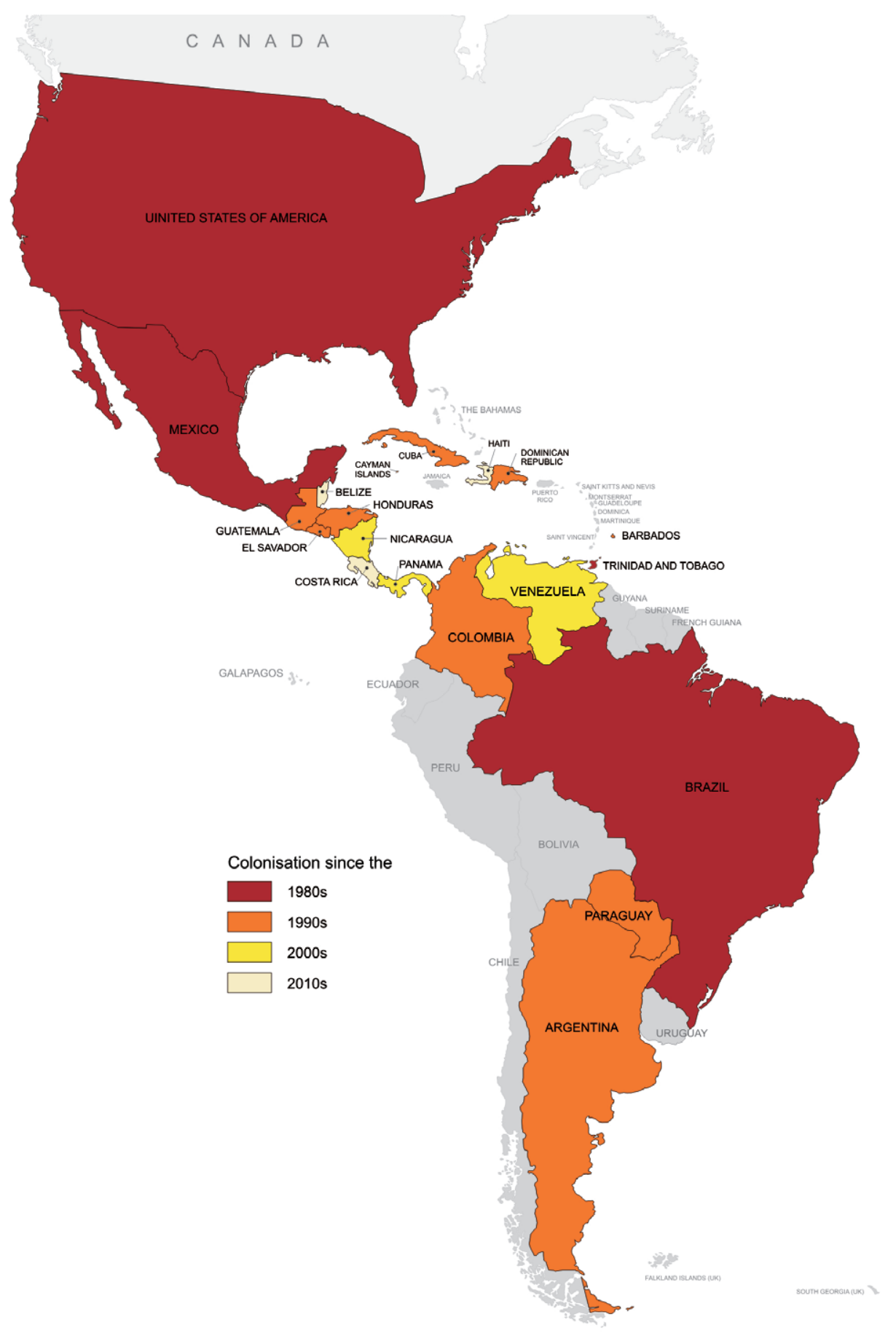

Fig. 3: American countries infested with Aedes albopictus.

dad and northeastern Argentina, in South America, and in all mainland countries in Central America, i.e., Panama, Costa Rica, Honduras, Nicaragua, Guatemala, El Salvador and Belize. In addition, it has also been confirmed in the Dominican Republic, Cuba, Haiti, Barbados, Cayman Islands, and in the USA and Mexico, in North America (Benedict et al. 2007, Navarrro et al. 2009, Calderón-Arguedas et al. 2010, Fernández et al. 2012, Wagman et al. 2013, MSES 2014). In Uruguay, a few Ae. albopictus were once detected near the Brazilian border, however subse- quent efforts have failed to confirm the colonisation of the country by this species (apud Lourenço-de-Oliveira et al. 2013). Similarly, the occurrence of this mosquito in Bolivia, in South America, as previously suggested as infested by Benedict et al. (2007), has never been confirmed. The occurrence of Ae. albopictus in Puerto Rico has also been suggested (Cook et al. 2006).

To date, Ae. aegypti mosquitoes are the only confirmed natural vectors of DENV and CHIKV in the Americas (Consoli \& Lourenço-de-Oliveira 1994, de 
Castro et al 2012, Nasci 2014). However, regional dynamics as well as special climate and environmental conditions might favour the proliferation and spread of Ae. albopictus, even leading to the displacement of Ae. aegypti in certain places (Gilotra et al. 1967, Lounibos et al. 2002). Under such conditions, Ae. albopictus may assume an important epidemiological role (Powell \& Tabachnick 2013). Incidentally, in Gabon (Pagès et al. 2009) and Cameroon (Simard et al. 2005), Ae. albopictus has become the most frequent mosquito species, overcoming Ae. aegypti in density and assuming the role of the primary vector of CHIKV. Moreover, Ae. albopictus became the primary (or only) natural vector in locations where Ae. aegypti is scarce or absent, which occurred during the epidemics of CHIKV in European countries such as Italy in 2007 (Carrieri et al. 2011) and France in 2010 (Gould et al. 2010), Indian Ocean islands such as Mauritius in 2006 (CDC 2008), Mayotte in 2005 and 2006 (Sissoko et al. 2008) and La Reunion in 2005 and 2006 (Renault et al. 2007, Thiboutot et al. 2010).

Because of the ability of Ae. albopictus females to move between wild and human-made environments while searching for oviposition sites and blood sources, this mosquito has been considered a potential vector of arboviruses for humans still restricted to the sylvan environment (Moore \& Mitchell 1997, Lourenço-deOliveira et al. 2003, Maciel-de-Freitas et al. 2006). In fact, experiments have revealed that Ae. albopictus competently transmits several arboviruses such as Eastern equine encephalitis, Mayaro, Western equine encephalitis, Venezuelan equine encephalitis, CHIKV, Ross River and Sindbis, DENV, Japanese encephalitis, YFV and West Nile fever (Mitchell \& Miller 1990, Smith \& Francy 1991, Mitchell et al. 1992, Forattini 2002, Holick et al. 2002, Lourenço-de-Oliveira et al. 2003, Fernández et al. 2003, Gratz 2004, Vazeille et al. 2007, Pessoa et al. 2013). Ae. albopictus is a natural vector of DENV in certain areas of Asia and has caused small epidemics in Europe. Furthermore, it is natural vector of CHIKV in Central Africa and Mediterranean Europe (Hawley 1988, WHO 2006, Delatte et al. 2008, Paupy et al. 2009, Tomasello \& Schlagenhauf 2013).

Therefore, the wide geographic distribution of $A e$. albopictus in the urban and suburban areas of Brazil and other American countries is a potential threat for arbovirus control in the new world. In Brazil, the range of $A e$. albopictus includes mostly the busiest international ports and airports as well as the largest road and railway networks located in the Southeast. Furthermore, the highest $\mathrm{HI}$ values for this mosquito was recorded in the Southeast. Therefore, the large distribution and high frequency of $A e$. albopictus might become a critical factor in the spread of arboviruses in Brazil. The current epidemics of CHIKV in some Caribbean islands that began in October 2013, as well as the growing number of imported CHIKV cases to mainland American countries like Brazil already infested with Ae. albopictus mosquitoes competent to transmit two CHIKV genotypes (Vega-Rua et al. 2014) are real threats to the spread of this arbovirus in the Americas. This situation illustrates the imperative need to strengthen research concerning the vectorial capacity of local Ae. albopictus populations to transmit CHIKV (Lambrechts \& Failloux
2012), in addition to designing entomological surveillance and control measures focusing on Ae. albopictus in Brazil and other infested American countries.

\section{ACKNOWLEDGEMENTS}

To Giovanini E Coelho and Rodrigo L. Frutuoso, from PNCD, for their support and for the availability of data from SISFAD and LIRAa, to Fred Lobo and Leônidas Leite, for their help in preparing the figures, to the coordinators of the PNCD from all Brazilian states and teams of the Health Secretaries of all municipalities and states involved in this study for their support and data on mosquito infestation, and to Gabriela Willat, Tamara Chávez, Ernesto Pleites and Maria Virginia Introini, for the information on Ae. albopictus occurrence in their respective countries.

\section{REFERENCES}

Aguiar DB, Fontão A, Rufino P, Macedo VA, Ríos-Velásquez CM, Castro MG, Honório NA 2008. Primeiro registro de Aedes albopictus (Diptera: Culicidae) em Roraima, Brasil. Acta Amazon 38: $357-360$.

Albuquerque CM, Melo-Santos MA, Bezerra MA, Barbosa RM, Silva DF, da Silva E 2000. Primeiro registro de Aedes albopictus em área da Mata Atlântica, Recife, PE, Brasil. Rev Saude Publica 34: $314-315$.

Benedict MQ, Levine RS, Hawley WA, Lounibos LP 2007. Spread of the tiger: global risk of invasion by the mosquito Aedes albopictus. Vector Borne Zoonotic Dis 7: 76-85.

Braks MA, Honório NA, Lourenço-de-Oliveira R, Juliano SA, Lounibos LP 2003. Convergent habitat segregation of Aedes aegypti and Aedes albopictus (Diptera: Culicidae) in southeastern Brazil and Florida. J Med Entomol 40: 785-794.

Calderón-Arguedas O, Avendaño A, López-Sánches W, Troyo A 2010. Expansion of Aedes albopictus skull in Costa Rica. Revista Ibero-Latinoamericana de Parasitologia 69: 220-222.

Carrieri M, Albieri A, Angelini P, Baldacchini F, Venturelli C, Zeo SM, Bellini R 2011. Surveillance of the chikungunya vector Aedes albopictus (Skuse) in Emilia-Romagna (northern Italy): organizational and technical aspects of a large scale monitoring system. J Vector Ecol 36: 108-116.

CDC - Center for Disease Control and Prevention 2008. Chikungunya fever, Mauritius, 2006. Emerg Infect Dis 14: 337-338.

Coelho GE 2012. Challenges in the control of Aedes aegypti. Rev Inst Med Trop Sao Paulo 54 (Suppl. 18): 13-14.

Consoli R, Lourenço-de-Oliveira R 1994. Principais mosquitos de importância sanitária no Brasil, Ed. Fiocruz, Rio de Janeiro, 225 pp.

Cook S, Bennett SN, Holmes EC, de Chesse R, Moureau G, Lamballerie X 2006. Isolation of a new strain of the flavivirus cell fusing agent virus in a natural mosquito population from Puerto Rico. J Gen Virol 87: 735-748.

de Castro MG, Nogueira RMR, de Filippis AMB, Ferreira AA, Lima MRQ, Faria NRC, Nogueira FB, Simões JBS, Nunes PCG, Sampaio SA, Lourenço-de-Oliveira R, dos Santos FB 2012. Dengue virus type 4 in Niterói, Rio de Janeiro: the role of molecular techniques in laboratory diagnosis and entomological surveillance. Mem Inst Oswaldo Cruz 107: 940-945.

Delatte H, Paupy C, Dehecq JS, Thiria J, Failloux AB, Fontenille D 2008. Aedes albopictus, vector of chikungunya and dengue viruses in Reunion Island: biology and control. Parasite 15: 3-13.

dos Santos RL 2003. Atualização da distribuição de Aedes albopictus no Brasil (1997-2002). Rev Saude Publica 37: 671-673. 
Estrada-Franco JG, Craig Jr GB 1995. Biology, disease relationships and control of Aedes albopictus, Pan American Health Organization, Washington, $49 \mathrm{pp}$.

Fernández MCM, Jean YS, Callaba CAF, López LS 2012. The first report of Aedes (Stegomyia) albopictus in Haiti. Mem Inst Oswaldo Cruz 107: 279-281.

Fernández Z, Moncayo AC, Carrara AS, Forattini OP, Weaver SC 2003. Vector competence of rural and urban strains of Aedes (Stegomyia) albopictus (Diptera: Culicidae) from São Paulo state, Brazil for IC, ID and IF subtypes of Venezuelan equine encephalitis virus. J Med Entomol 40: 522-527.

Forattini OP 2002. Culicidologia médica, Vol. 2, Universidade de São Paulo, São Paulo, 864 pp.

Forattini OP, Kakitani I, dos Santos RL, Kobayashi KM, Ueno HM, Fernandez Z 2000. Adults Aedes albopictus and Ae. scapularis behavior (Diptera: Culicidae) in southeastern Brazil. Rev Saude Publica 34: 461-467.

Gilotra SK, Rozeboom LE, Bhattacharya NC 1967. Observations on possible competitive displacement between populations of Aedes aegypti Linnaeus and Aedes albopictus Skuse in Calcutta. Bull World Health Organ 37: 437-446.

Gould EA, Gallian P, de Lamballerie X, Charrel RN 2010. First cases of autochthonous dengue fever and chikungunya fever in France: from bad dream to reality! Clin Microbiol Infect 16: 1702-1704.

Gratz NG 2004. Critical review of the vector status of Aedes albopictus. Med Vet Entomol 18: 215-227.

Hawley WA 1988. The biology of Aedes albopictus. J Am Mosq Control Assoc 1 (Suppl.): S1-S39.

Holick J, Kyle A, Ferraro W, Delaney RR, Iwaseczko M 2002. Discovery of Aedes albopictus infected with West nile virus in southeastern Pennsylvania. J Am Mosq Control Assoc 18: 131.

Honório NA, Castro MG, Barros FS, Magalhães MA, Sabroza PC 2009. The spatial distribution of Aedes aegypti and Aedes albopictus in a transition zone, Rio de Janeiro, Brazil. Cad Saude Publica 25: 1203-1214.

Juliano SA, Lounibos LP 2005. Ecology of invasive mosquitoes: effects on resident species and on human health. Ecol Lett 8: 558-574.

Lambrechts L, Failloux A-B 2012. Vector biology prospects in dengue research. Mem Inst Oswaldo Cruz 107: 1080-1082.

Lima-Camara TN, Codeço CT, Honório NA, Bruno RV, Peixoto AA, Lounibos LP 2013. Male accessory gland substances from Aedes albopictus affect the locomotor activity of Aedes aegypti females. Mem Inst Oswaldo Cruz 108 (Supp1. I): S18-S25.

Lounibos LP 2002. Invasions by insect vectors of human disease. Annu Rev Entomol 47: 233-266.

Lounibos LP, Escher RL, Lourenço-de-Oliveira R 2003. Asymmetric evolution of photoperiodic diapause in temperate and tropical populations of Aedes albopictus (Diptera: Culicidae). Ann Entomol Soc Am 96: 512-518.

Lounibos LP, Suárez S, Menéndez Z, Nishimura N, Escher RL, O'Connell SM, Rey JR 2002. Does temperature affect the outcome of larval competition between Aedes aegypti and Aedes albopictus? J Vector Ecol 27: 86-95.

Lourenço-de-Oliveira R, Castro MG, Braks MA, Lounibos LP 2004. The invasion of urban forest by dengue vectors in Rio de Janeiro. J Vector Ecol 29: 94-100.

Lourenço-de-Oliveira R, Vazeille M, de Filippis AM, Failloux AB 2003. Large genetic differentiation and low variation in vector competence for dengue and yellow fever viruses of Aedes al- bopictus from Brazil, the United States and the Cayman Islands. Am J Trop Med Hyg 69: 105-114.

Lourenço-de-Oliveira R, Vega-Rua A, Vezzani D, Willat G, Vazeille M, Mousson L, Failloux AB 2013. Aedes aegypti from temperate regions of South America are highly competent to transmit dengue vírus. BMC Infectious Diseases 13: 610.

Maciel-de-Freitas R, Neto RB, Gonçalves JM, Codeço CT, Lourençode-Oliveira R 2006. Movement of dengue vectors between the human modified environment and an urban forest in Rio de Janeiro. J Med Entomol 43: 1112-1120.

Medlock JM, Hansford KM, Schaffner F, Versteirt V, Hendrickx G, Zeller H, Bortel WV 2012. A review of the invasive mosquitoes in Europe: ecology, public health risks and control options. Vector-Borne Zoonotic Dis 12: 435-447.

Miller BR, Mitchell CJ, Ballinger ME 1989. Replication, tissue tropisms and transmission of yellow fever virus in Aedes albopictus. Trans R Soc Trop Med Hyg 83: 252-255.

Mitchell CJ, Miller BR 1990. Vertical transmission of dengue viruses by strains of Aedes albopictus recently introduced into Brazil. $J$ Am Mosq Control Assoc 6: 251-253.

Mitchell CJ, Miller BR, Gubler DJ 1987. Vector competence of Aedes albopictus from Houston, Texas, for dengue serotypes 1 to 4, yellow fever and Ross River viruses. J Am Mosq Control Assoc 3: 460-465.

Mitchell CJ, Niebylski ML, Smith GC, Karabatsos N, Martin D, Mutebi JP, Craig Jr GB, Mahler MJ 1992. Isolation of Eastern equine encephalitis virus from Aedes albopictus in Florida. Science 257: 526-527.

Moore CG, Mitchell CJ 1997. Aedes albopictus in the United States: ten-year presence and public health implications. Emerg Infect Dis 3: 329-334.

MS - Ministério da Saúde Brasil 2005. Diagnóstico rápido nos municípios para vigilância entomológica do Aedes aegypti no Brasil - LIRAa. Metodologia para avaliação dos índices de Breteau e predial, Secretaria de Vigilância Sanitária, Brasília, 58 pp.

MS - Ministério da Saúde Brasil 2006. Nota Técnica 24/2006 CGPNCD/DIGES/SVS/MS, MS, Brasília, 17 pp.

MS - Ministério da Saúde Brasil 2009. Diretrizes nacionais para prevenção e controle de epidemias de dengue. Available from: bvsms.saude.gov.br/bvs/publicacoes/diretrizes_nacionais_prevencao_controle_dengue.pdf.

MSES - Ministerio de Salud de El Salvador 2014. Lineamientos técnicos para la prevención y control de la fiebre chikungunya, Ministerio de Salud/Viceministerio de Políticas de Salud, San Salvador, $45 \mathrm{pp}$.

Nasci RS 2014. Movement of Chikungunya virus into the Western hemisphere. Emerg Infect Dis 20: 1394-1395.

Natal D, Urbinatti PR, Taipe-Lagos CB, Cereti-Junior W, Diederich ATB, Souza RG, Souza RP 1997. Encontro de Aedes (Stegomyia) albopictus (Skuse) em Bromeliaceae na periferia de São Paulo, SP, Brasil. Rev Saude Publica 31: 517-518.

Navarrro JC, Zorrilla A, Moncada N 2009. Primer registro de Aedes albopictus (Skuse) en Venezuela. Importancia como vector de Dengue y acciones a desarrollar. Bol Mal Salud Amb 49: 161-166.

Pagès F, Peyrefitte CN, Mve MT, Jarjaval F, Brisse S, Iteman I, Gravier P, Tolou H, Nkoghe D, Grandadam M 2009. Aedes albopictus mosquito: the main vector of the 2007 chikungunya outbreak in Gabon. PLoS ONE 4: e4691.

Paupy C, Delatte H, Bagny L, Corbel V, Fontenille D 2009. Aedes albopictus, an arbovirus vector: from the darkness to the light. Microbes Infect 11: 1177-1185. 
Pessoa MVE, Silveira DA, Cavalcante IL, Florindo MI 2013. Aedes albopictus no Brasil: aspectos ecológicos e riscos de transmissão da dengue. Entomotropica 28: 75-86.

Pilger D, Lenhart A, Manrique-Saide P, Siqueira JB, da Rocha WT, Kroeger A 2011. Is routine dengue vector surveillance in central Brazil able to accurately monitor the Aedes aegypti population? Results from a pupal productivity survey. Trop Med Int Health 16: $1143-1150$

Powell JR, Tabachnick WJ 2013. History of domestication and spread of Aedes aegypti - A Review. Mem Inst Oswaldo Cruz 108 (Suppl. I): $11-17$.

Prophiro JS, Silva OS, Luna JED, Piccoli CF, Kanis LA, Navarro-Silva MA 2011. Aedes aegypti and Aedes albopictus (Diptera: Culicidae): coexistence and susceptibility to temephos in municipalities with occurrence of dengue and differentiated characteristics of urbanization. Rev Soc Bras Med Trop 44: 300-305.

Reiter P 1998. Aedes albopictus and the world trade in used tires, 1988-1995: the shape of things to come? J Am Mosq Control Assoc 14: 83-94.

Reiter P, Sprenger D 1987. The used tire trade: a mechanism for the worldwide dispersal of container breeding mosquitoes. $J \mathrm{Am}$ Mosq Control Assoc 3: 494-501.

Renault P, Solet JL, Sissoko D, Balleydier E, Larrieu S, Filleul L, Lassalle C, Thiria J, Rachou E, de Valk H, Ilef D, Ledrans M, Quatresous I, Quenel P, Pierre V 2007. A major epidemic of Chikungunya virus infection on Réunion Island, France, 2005-2006. Am J Trop Med Hyg 77: 727-731.

Simard F, Nchoutpouen E, Toto JC, Fontenille D 2005. Geographic distribution and breeding site preference of Aedes albopictus and Aedes aegypti (Diptera: Culicidae) in Cameroon, Central Africa. $J$ Med Entomol 42: 726-731.

Sissoko D, Malvy D, Giry C, Delmas G, Paquet C, Gabrie P, Pettinelli F, Sanquer MA, Pierre V 2008. Outbreak of chikungunya fever in Mayotte, Comoros archipelago, 2005-2006. Trans R Soc Trop Med Hyg 102: 780-786.

Smith GC, Francy DB 1991. Laboratory studies of a Brazilian strain of Aedes albopictus as a potential vector of Mayaro and Oropouche viruses. J Am Mosq Control Assoc 7: 89-93.
Sprenger D, Wuithiranyagool T 1986 . The discovery and distribution of Aedes albopictus in Harris County, Texas. J Am Mosq Control Assoc 2: 217-219.

Thiboutot MM, Kannan S, Kawalekar OU, Shedlock D, Khan A, Sarangan G, Muthumani K 2010. Chikungunya: a potentially emerging epidemic? PLOS Negl Trop Dis 4: e623.

Tomasello D, Schlagenhauf P 2013. Chikungunya and dengue autochthonous cases in Europe, 2007-2012. Travel Med Infect Dis 11: 274-284.

Usmani-Brown S, Cohnstaedt L, Munstermann LE 2009. Population genetics of Aedes albopictus (Diptera: Culicidae) invading populations using mitochondrial nicotinamide adenine dinucleotide dehydrogenase subunit 5 sequences. Ann Entomol Soc Am 102: 144-150.

Vazeille M, Moutailler S, Coudrier D, Rousseaux C, Khun H, Huerre M, Thiria J, Dehecq JS, Fontenille D, Schuffenecker I, Despres P, Failloux AB 2007. Two chikungunya isolates from the outbreak of La Reunion (Indian Ocean) exhibit different patterns of infection in the mosquito, Aedes albopictus. PLoS ONE 2: e1168.

Vega-Rua A, Zouache K, Girod R, Failloux AB, Lourenço-de-Oliveira R 2014. High level of vector competence of Aedes aegypti and Aedes albopictus from ten American countries as a crucial factor in the spread of Chikungunya virus. J Virol 88: 6294-6306.

Vidal PO, Carvalho E, Suesdek L 2012. Temporal variation of wing geometry in Aedes albopictus. Mem Inst Oswaldo Cruz 107: 1030-1034.

Wagman J, Grieco JP, King R, Briceño I, Bautista K, Polanco J, Pecor J, Achee NL 2013. First record and demonstration of a southward expansion of Aedes albopictus into Orange Walk Town, Belize, Central America. J Am Mosq Control Assoc 29: 380-382.

WHO - World Health Organization 2006. Chikungunya in Mauritius, Seychelles, Mayotte (France) and La Réunion island (France). Global alert and response. Available from: who.int/csr/ don/2006_03_01/en/.

WHO - World Health Organization 2009. Dengue. Guidelines for diagnosis, treatment, prevention and control. Available from: who.int/tdr/publications/documents/dengue-diagnosis.pdf.

Zeller HG 1998. Dengue, arboviruses and migrations in the Indian Ocean. Bull Soc Pathol Exot 91: 56-60. 